\title{
O tempo entre ficção e filosofia: sobre a História do cerco de Lisboa, de José Saramago
} MARCELO LACHAT ${ }^{I}$

Quid est ergo tempus? Si nemo ex me quaerat, scio; si quaerenti explicare velim, nescio.

[O que é o tempo, então? Se ninguém me perguntar, eu sei; mas, se eu quiser explicar a alguém que me pergunte, não sei].

(Agostinho. 2017, XI, XIV, 17).

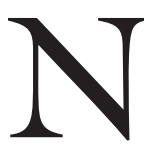

A História do cerco de Lisboa, romance de José Saramago publicado em 1989, há três estratos temporais que se atravessam: o do narrador, o de

Raimundo Benvindo Silva e Maria Sara e o de Mogueime e Ouroana. Este último é o único que tem uma data bem definida: 1147, ano em que ocorreu o chamado "cerco de Lisboa", evento histórico que culminou (de acordo com uma perspectiva eurocêntrica e cristã) na "reconquista" da cidade, então dominada pelos "mouros"; para essa tomada de Lisboa, os portugueses, comandados por D. Afonso Henriques, contaram com o auxílio dos cruzados. Já aquele primeiro estrato temporal, o do narrador do romance, é indefinível, presentificando-se a cada leitura; enquanto o segundo, concernente à história de Raimundo Silva e Maria Sara, dá-se num passado próximo, que ainda hoje pode ser considerado contemporâneo. Embora as três camadas de tempo dessa obra saramaguiana sejam ficcionais, elas são concebidas, neste trabalho, à semelhança dos “estratos do tempo" propostos por Reinhart Koselleck (2014, p.9) no campo da historiografia, os quais "remetem a diversos planos, com durações diferentes e origens distintas, mas que, apesar disso, estão presentes e atuam simultaneamente". Assim, eles permitem "reunir em um mesmo conceito a contemporaneidade do não contemporâneo, um dos fenômenos históricos mais reveladores. Muitas coisas acontecem ao mesmo tempo, emergindo, em diacronia ou em sincronia, de contextos completamente heterogêneos” (ibidem).

Posto isso, é preciso ressaltar que as relações entre ficção e história na produção literária de Saramago já foram amplamente analisadas por pesquisadores como Teresa Cristina Cerdeira da Silva (1989), Ana Paula Arnaut (1996) e Aparecida de Fátima Bueno (1999). Ademais, pode-se recordar que, para Linda Hutcheon (1991, p.141ss.), um aspecto fundamental da "poética do pós-modernismo" seria justamente a "metaficção historiográfica”, cuja importância no romance português contemporâneo - e, particularmente, na História do cerco 
de Lisboa - é discutida por Arnaut (2002, p.295ss.). Nesse sentido, cabe ainda lembrar o estudo de Márcia Gobbi (2011), o qual, a partir dos conceitos de mito e de paródia, trata da ficcionalização da história na narrativa portuguesa contemporânea.

Todavia, o que se propõe neste artigo, tendo em vista aqueles estratos temporais e levando em consideração essas relações entre ficção e história na literatura portuguesa contemporânea (em especial, na prosa), é uma discussão - mais filosófica e menos historiográfica - a respeito da concepção de tempo na História do cerco de Lisboa. Essa reflexão pautada pela filosofia parece pertinente, entre outras coisas, porque o próprio personagem central do romance, o revisor Raimundo Silva, admite sua "vocação para ser filósofo" (Saramago, 2019, p.79) - não se devendo desconsiderar, evidentemente, a ironia desse trecho; ironia, aliás, que permeia toda a obra. O revisor chega a essa conclusão ao lembrar-se de um diálogo que teve com o historiador, autor do livro historiográfico sobre o cerco de Lisboa a ser revisado. Nesse diálogo, que se dá nas primeiras páginas do romance, Raimundo Silva elucubra acerca da relevância do ofício que ele exerce: "Porque os tempos deixaram de ser noite de si mesmos quando as pessoas começaram a escrever, ou a emendar, torno a dizer, que é obra doutro requinte e outra transfiguração"; ao que responde o historiador: "Creio perceber nas suas palavras uma certa amargura cética"; e emenda o revisor: "Vejo-a mais como um ceticismo amargo" (ibidem, p.12). Como um filósofo cético, Raimundo Silva emprega a ironia para questionar as (supostas) verdades históricas, pois, segundo ele mesmo, "tudo quanto não for vida, é literatura, [...] A história sobretudo, sem querer ofender" (ibidem, p.13). Esse ceticismo irônico, que instaura a dúvida constante, evidencia-se já na epígrafe do romance: "Enquanto não alcançares a verdade, não poderás corrigi-la. Porém, se a não corrigires, não a alcançarás. Entretanto, não te resignes". Feito filósofo, enfim, o revisor medita sobre o tempo e o historiador lhe assinala a vocação: "É o que tem o tempo, corre e não damos por ele, está uma pessoa por aí ocupada nos seus quotidianos, subitamente cai em si e exclama, meu Deus, como o tempo passa, ainda agora estava o rei Salomão vivo e já lá vão três mil anos, Quer-me parecer que você errou a vocação, devia era ser filósofo, ou historiador, [...] Meta-se a filósofo, homem" (ibidem, p.14-15).

A ironia que constitui a História do cerco de Lisboa não é apenas um instrumento filosófico de questionamento da verdade, mas também um procedimento linguístico (e literário) que é assim definido por Hutcheon (1995, p.11):

Irony, then, will mean different things to the different players. From the point of view of the interpreter, irony is an interpretive and intentional move: it is making or inferring of meaning in addition to and different from what is stated, together with an attitude toward both the said and the unsaid. The move is usually triggered (and then directed) by conflictual textual or contextual evidence or by markers which are socially agreed upon. However, from the point of view of what I too (with reservations) will call the ironist, irony is the 
intentional transmission of both information and evaluative attitude other than what is explicitly presented. (grifos da autora) ${ }^{1}$

Desse modo, o "não" que Raimundo Silva acrescenta ao livro do historiador determina, por meio de ironia histórica, filosófica e ficcional, que os cruzados não ajudaram os portugueses no cerco de Lisboa; ou seja, empregando-se os citados termos de Hutcheon, esse irônico "não" do revisor transmite, intencionalmente, uma informação e uma atitude avaliativa que estão além daquilo que é apresentado de forma explícita. Como sintetiza o narrador do romance, "agora o que o livro passou a dizer é que os cruzados Não auxiliarão os portugueses a conquistar Lisboa, assim está escrito e portanto passou a ser verdade, ainda que diferente, o que chamamos falso prevaleceu sobre o que chamamos verdadeiro, tomou o seu lugar" (Saramago, 2019, p.53). Por isso, o "não" de Raimundo Silva desconstrói a história portuguesa tradicionalmente aceita e estabelece uma nova verdade, constituída de irônicas incertezas, e um novo tempo em que passado, presente e futuro se fundem indefiníveis.

No entanto, para compreender-se essa concepção temporal da História do cerco de Lisboa, é necessário ter em mente que são, filosófica e historicamente, diversas as noções de tempo. Na teologia cristã, Deus, que está fora do tempo, foi quem o criou e é a sua causa onipresente; por conseguinte, em todos os acontecimentos históricos há a presença divina. O sentido (primeiro e último) da história e do próprio tempo é, portanto, Deus. Em suas Confissões, Agostinho (2017, p.318) declara, por exemplo, que "tu [Deus] fizeste todo o tempo e és antes de todo tempo, e não houve um tempo em que não havia tempo. Logo, não houve um tempo em que não fizesses algo, porque tu fizeste o próprio tempo. E nenhum tempo é coeterno contigo, porque tu permaneces; mas ele, se permanecesse, não seria tempo". Em seguida, o mesmo Agostinho questiona-se sobre em que consiste propriamente o tempo:

O que é o tempo, então? Se ninguém me perguntar, eu sei; mas, se quiser explicar a alguém que me pergunte, não sei: mas é com segurança que afirmo saber que, se nada passasse, não haveria tempo passado; se nada sobreviesse, não haveria tempo futuro; e, se nada fosse, não haveria tempo presente. Logo, aqueles dois tempos, passado e futuro, em que sentido eles são, se o passado não é mais, e o futuro ainda não é? Mas o presente, se fosse sempre presente e não se tornasse passado, não seria presente, e sim eternidade. Logo, se o presente, para que seja tempo, há de se tornar passado, como podemos dizer, a respeito dele também, que é, se a razão de sua existência é deixar de ser? De maneira que não afirmamos com verdade que o tempo é, senão porque ele tende a não ser. (ibidem, p.319)

Respondendo a esses questionamentos, conclui Agostinho que, não se podendo conceber nem o futuro nem o passado, o que há, rigorosamente, são três tempos: "o presente do passado, o presente do presente e o presente do futuro. Esses três, de fato, estão na alma, de alguma maneira, e não os vejo em outro lugar: a memória presente do passado, a visão presente do presente, a expectativa 
presente do futuro" (ibidem, p.324). Assim, o tempo não está nas coisas, mas somente na alma (anima), presentificando-se como memória (memoria), visão (contuitus) e expectativa (expectatio).

As concepções teológicas de tempo prevalecem até fins do século XVIII, quando se consolida a noção de progresso, que delas se desvencilha e na qual "se procurou reunir grande número de novas experiências dos três séculos anteriores. O conceito de progresso único e universal nutria-se de muitas novas experiências individuais de progressos setoriais, que interferiam com profundidade cada vez maior na vida quotidiana e que antes não existiam" (Koselleck, 2006, p.317). Apreende-se o tempo, a partir de então, predominantemente, como progresso, sendo a Revolução Francesa um grande marco dessa nova concepção temporal: desde o final do Setecentos, o conceito de "revolução" não comporta a repetição do passado, implicando, pelo contrário, a busca pela ruptura da continuidade. Isso porque "as expectativas para o futuro se desvincularam de tudo quanto as antigas experiências haviam sido capazes de oferecer. $\mathrm{E}$ as experiências novas $[\ldots]$ já não eram suficientes para servir de base a novas expectativas para o futuro" (ibidem, p. 318). Daí o "espaço de experiência" não ser mais limitado pelo "horizonte de expectativa", projetando-se um futuro inédito, num tempo cada vez mais acelerado.

Nesse sentido, o texto Ideia de uma história universal de um ponto de vista cosmopolita (1784), de Immanuel Kant (1986), é considerado o escrito inaugural da filosofia da história alemã e um dos primeiros a sustentar, filosoficamente, esse novo conceito do tempo (histórico) como progresso. Nele, o autor afirma que as ações humanas são determinadas por leis naturais universais, as quais indicam "um desenvolvimento continuamente progressivo" das disposições originais de toda a espécie. Por isso, seria tarefa do filósofo "descobrir, neste curso absurdo das coisas humanas, um propósito da natureza que possibilite, todavia, uma história segundo um determinado plano da natureza para criaturas que procedem sem um plano próprio" (Kant, 1986, p.10). Para tanto, Kant apresenta nove proposições. A oitava assenta que é possível "considerar a história da espécie humana, em seu conjunto, como a realização de um plano oculto da natureza para estabelecer uma constituição política (Staatsverfassung) perfeita interiormente e, quanto a este fim, também exteriormente perfeita, como o único estado no qual a natureza pode desenvolver plenamente, na humanidade, todas as suas disposições" (ibidem, p.20). Kant propõe, então, uma perspectiva historiográfica teleológica: a história como realização de um plano oculto da natureza; e o tempo histórico pode ser acelerado, por meio da "disposição racional" humana, para se alcançar mais rapidamente tal finalidade, que é, nas palavras do filósofo prussiano, "o advento de uma era tão feliz para os nossos descendentes". O propósito supremo da natureza, ao qual a história visa, é, enfim, "um estado cosmopolita universal, como o seio no qual podem se desenvolver todas as disposições originais da espécie humana”. Daí apontar a nona e 
última proposição desse texto kantiano para a viabilidade de "uma tentativa filosófica de elaborar a história universal do mundo segundo um plano da natureza que vise à perfeita união civil na espécie humana" (ibidem, p.22). Seria essa, em suma, uma "história filosófica" (ibidem, p.24).

A noção de tempo como progresso (e também como evolução) embasa, ainda que de forma implícita - e com diversas nuances, evidentemente -, importantes discussões filosóficas do século XIX: por exemplo, a dialética de Hegel, ${ }^{2}$ o positivismo de Comte ${ }^{3}$ e o materialismo histórico de Marx e Engels. ${ }^{4}$ Porém, na segunda de suas quatro "considerações extemporâneas", intitulada Sobre a utilidade e a desvantagem da história para a vida (1874), Friedrich Nietzsche (2014, p.30) rompe com tal noção e critica o excesso de "sentido histórico" dos pensadores de sua época, exagero que conduziria a "uma cômoda renúncia da vida e da ação" e à "edulcoração da vida egoísta ou do ato covarde e vil", pois "é apenas na medida em que a história serve à vida que queremos a ela servir; mas existe um grau, no exercício e na valorização da história, em que a vida fenece e se degenera". Ainda de acordo com o filósofo, há três maneiras possíveis de se relacionar com o tempo: a-histórica, histórica e supra-histórica. A primeira é como os animais vivem:

Observe o rebanho a pastar: ele nada sabe do que é ontem e o hoje; saltita aqui e acolá, come, descansa, digere, novamente saltita, noite e dia, dia após dia. Em resumo, preso ao seu prazer e desprazer, estancado no instante, não se entristece nem se enfastia. Ver isso é difícil para o homem, que se vangloria de sua humanidade perante o animal, mas contempla enciumado a sorte deste - pois o homem apenas quer, como o animal, viver sem fastio e sem dor; mas o quer em vão, por não querer como aquele. (ibidem, p.33)

Quanto à segunda maneira, ela diz respeito aos homens históricos: estes "creem que o sentido da existência sairá à luz paulatinamente no decurso de um processo; por isso eles só olham para trás, a fim de entender o presente pela consideração do processo até o momento, e aprendem a desejar ansiosamente o futuro" (ibidem, p.42). Finalmente, a terceira é a dos homens supra-históricos, que conseguem ver aquilo que é eterno; para eles, "o passado e o presente são uma e mesma coisa, ou seja, em toda multiplicidade, são tipicamente iguais e, como uma onipresença de tipos perpétuos, são uma imagem paralisada de valor invariável e de significado eternamente idêntico" (ibidem, p.43).

Nesse texto, Nietzsche ataca, em suma, tanto a filosofia positivista, que entende a história como ciência objetiva e neutra, quanto a concepção teleológica hegeliana, que toma a história como progresso do espírito. Desse modo, a crítica ao excesso de sentido histórico e à ideia de progresso na segunda "consideração extemporânea" suscita, como possível contraposição lógica - que não aparece nesse escrito -, um dos conceitos mais relevantes (e mais difíceis) da filosofia nietzschiana: o eterno retorno. Em Assim falou Zaratustra, encontra-se um dos principais esboços de tal conceito: 
Pois teus animais bem sabem, ó Zaratustra, quem tu és e tens de tornar-te: eis que és o mestre do eterno retorno - é esse agora o teu destino!

Que tenhas de ser o primeiro a ensinar essa doutrina - como esse grande destino não seria também teu maior perigo e maior doença?

Vê, sabemos o que ensinas: que todas as coisas eternamente retornam, e nós mesmos com elas, e que eternas vezes já estivemos aqui, juntamente com todas as coisas.

Ensinas que há um grande ano do vir-a-ser, uma monstruosidade de grande ano: tal como uma ampulheta, ele tem de virar sempre de novo, a fim de novamente escorrer e transcorrer: -

- de modo que todos esses anos são iguais a si mesmos, nas coisas maiores e também nas menores - de modo que nós mesmos somos iguais a nós mesmos em cada grande ano, nas coisas maiores e também nas menores. (Nietzsche, 2018, p.211)

$\mathrm{Na}$ doutrina nietzschiana do eterno retorno, o tempo não é progressivo, e sim cíclico: todas as coisas, todas as pessoas e todas as ações retornam eternamente; tudo é sempre igual ao que foi, ao que é e ao que será.

Já no primeiro quartel do século XX, outra concepção filosófica de tempo que foge à ideia de progresso é a de Henri Bergson (2006), particularmente na sua obra Duração e simultaneidade (1922). Para discutir a natureza do tempo, o filósofo francês propõe o conceito de duração, que consiste em

[...] uma memória interior à própria mudança, memória que prolonga o antes no depois e os impede de serem puros instantâneos que aparecem e desaparecem num presente que renasceria incessantemente. Uma melodia que ouvimos de olhos fechados, pensando apenas nela, está muito perto de coincidir com esse tempo que é a própria fluidez de nossa vida interior; mas ainda tem qualidades demais, determinação demais, e seria preciso começar por apagar a diferença entre os sons, e depois abolir as características distintivas do próprio som, conservar dele apenas a continuação do que precede no que se segue e a transição ininterrupta, multiplicidade sem divisibilidade e sucessão sem separação, para encontrar por fim o tempo fundamental. Assim é a duração imediatamente percebida, sem a qual não teríamos nenhuma ideia de tempo. (Bergson, 2006, p.51-2)

A duração constitui, em última instância, o próprio tempo; e ambos são, posto que unos, multiplicidades virtuais (Deleuze, 2012, p.68-75). Além disso, “a duração é essencialmente uma continuação do que não é mais no que é. Eis aí o tempo real, ou seja, percebido e vivido. Eis também qualquer tempo concebido, pois não se pode conceber um tempo sem representá-lo percebido e vivido. Duração implica portanto consciência; e pomos consciência no fundo das coisas pelo fato de lhes atribuirmos um tempo que dura" (Bergson, 2006, p.57).

Esse tempo-duração bergsoniano, que só existe enquanto consciência, pode ser relacionado com aquele primeiro estrato temporal da História do cerco de Lisboa, isto é, o do narrador. Dessa maneira, as primeiras palavras do romance são 
justamente do narrador, as quais, ironicamente semelhantes àquelas do capítulo inicial de Gênesis, criam o tempo da ficção: "Disse o revisor" (Saramago, 2019, p.9). Se o tempo de Raimundo Silva e Maria Sara é o passado próximo indicado pelo verbo "disse" e o de Mogueime e Ouroana é o passado distante do cerco de Lisboa, em 1147, o da narração é a duração percebida e vivida por cada leitor no momento da leitura. Logo, o tempo da ficção é único e uno, porém, multiplicidade virtual, ele é composto de três camadas que são elas próprias diferentes tempos. E, para o narrador (irônico demiurgo), todo romance é uma busca pelo tempo que passou, apenas ele efetivamente tempo, embora sempre perdido:

Afinal, é apenas um romance entre os romances, não tem que preocupar-se mais com introduzir nele o que nele já se encontra, porque livros destes, as ficções que contam, fazem-se, todos e todas, com uma continuada dúvida, com um afirmar reticente, sobretudo a inquietação de saber que nada é verdade e ser preciso fingir que o é, ao menos por um tempo, até não se poder resistir à evidência inapagável da mudança, então vai-se ao tempo que passou, que só ele é verdadeiramente tempo, e tenta-se reconstituir o momento que não soubemos reconhecer, que passava enquanto reconstituíamos outro, e assim por diante, momento após momento, todo o romance é isso, desespero, intento frustrado de que o passado não seja coisa definitivamente perdida. (ibidem, p.61)

Uma visão assim deceptiva do romance como desespero e intento frustrado de reconstituir o passado é possível de ser aproximada à compreensão crítica de utopia apresentada por Emil Cioran, na obra Histoire et utopie [História e utopia] (1960). Para o filósofo romeno, “toutes les sociétés sont mauvaises" (Cioran, 2014, p.20); ${ }^{5}$ daí a necessidade da utopia, definida como um princípio de renovação das instituições e dos povos. Mais ainda: a vida sem utopia torna-se irrespirável, pelo menos para a "multidão"; e não há nada perfeito na história. Diante daquela maldade congênita das sociedades e desta imperfeição da história, a utopia (e, pode-se acrescentar, tal como o romance histórico) é uma ficção que adquire as virtudes de um dado primordial: "Ayant quitté la réalité pour l'idée, et l'idée pour l'idélogie, l'homme a glissé vers un univers dérivé, vers un monde de sous-produits, où la fiction acquiert les vertus d'une donnée primordiale" (ibidem, p.22). ${ }^{6}$ Conforme Cioran, uma sociedade subsiste somente na medida em que ela cria ficções, alimenta-as, preserva-as e a elas se liga fortemente. Entretanto, cada civilização acredita que seu modo de vida é o único bom e adequado, e que a esse modo ela deve converter o mundo, à força se for preciso; por esse motivo, o filósofo romeno afirma ser a utopia "une féerie monstrueuse" (ibidem, p.40).?

Além disso, especificamente quanto aos conceitos de tempo e de história, Cioran assevera que os tempos históricos só avançam pisoteando, esmagando as massas. Por conseguinte, deve-se concluir que a história não tem, absolutamente, uma essência angelical; na realidade, nela não se concebe outro desejo senão o de promover a amargura na dignidade de uma gnose: "Cadre où nous accomplissons le contraire de nos aspirations, ò̀ nous les défigurons sans cesse, l'Histoire 
n'est assurément pas d'essence angélique. À la considérer, nous ne concevons plus qu'un désir: promouvoir l'aigreur à la dignité d'une gnose" (ibidem, p.54-5).8 E se a sabedoria recomenda a felicidade dada, existente, o homem, por ser um "animal histórico", deseja a felicidade imaginada; consequentemente, os sonhos humanos de um mundo melhor fundam-se numa impossibilidade teórica:

De gré ou de force, nous misons sur l'avenir, en faisons une panacée, et, l'assimilant au surgissement d'un tout autre temps à l'intérieur du temps même, le considérons comme une durée inépuisable et pourtant achevée, comme une histoire intemporelle. Contradiction dans les termes, inhérente à l'espoir d'un règne nouveau, d'une victoire de l'insoluble au sein du devenir. Nos $r \hat{e}-$ ves d'un monde meilleur se fondent sur une impossibilité théorique. (ibidem, p.109) $)^{9}$

Contudo, o autor também aponta alguns méritos da utopia, sendo o principal deles denunciar os malfeitos da propriedade, o horror que ela representa, as calamidades de que ela é causa. Por isso, é um orgulho e uma revelação descobrir que nada pertence a ninguém: "Quelle fierté de découvrir que rien ne vous appartient, quelle révélation!" (ibidem, p.115). ${ }^{10}$

No sexto e último ensaio que compõe Histoire et utopie, Cioran trata da Idade de Ouro. Para tanto, cita inicialmente a descrição de Hesíodo em Os trabalhos e os dias e, em seguida, relaciona a Idade de Ouro ao Paraíso bíblico (do livro de Gênesis). Nos dois casos, de acordo com o filósofo romeno, o que reina é “o eterno presente", isto é, um tempo forjado por oposição à própria ideia de tempo. E, no mito da Idade de Ouro, foi Prometeu o responsável por arrancar o ser humano desse eterno presente. Para Cioran, então, a passagem das idades míticas (ouro, prata, bronze e ferro) marca a progressão da queda humana. Assim, “tombés sans recours dans l'éternité négative, dans ce temps éparpillé qui ne s'affirme qu'en s'annulant, essence réduite à une série de destructions, somme d'ambigüités, plénitude dont le principe réside dans le néant, nous vivons et mourons dans chacun de ses instants, sans savoir quand il est, car à la vérité il n'est jamais" (ibidem, p.126). ${ }^{11} \mathrm{O}$ ser humano vive e morre em cada um dos instantes da eternidade negativa, desse tempo disperso que só se afirma anulando-se; por ter caído da Idade de Ouro ou do Paraíso, o homem vive e morre no tempo sem saber quando é, pois na verdade nunca é. E, precisamente, o que a utopia busca conciliar é o eterno presente com a história. Portanto, "l'utopie est un rêve cosmogonique au niveau de l'histoire" (ibidem, p.130); ${ }^{12}$ mas a harmonia, universal ou não, nunca existiu nem jamais existirá.

Depois de toda essa devastação filosófica dos conceitos de utopia, história e tempo, Cioran revela, no final da obra, o único paraíso possível: "Point de paradis, sinon au plus profond de notre être, et comme dans le moi du moi". "Todavia, como questiona o próprio filósofo: esse novo paraíso no mais profundo do ser, e como que no "eu" do "eu”, não seria uma mera substituição daquele "fantasma" da Idade de Ouro por outro, isto é, pelo "eu original”, que evoca o vazio e, no fim das contas, a ele se reduz? A essa questão responde Cioran com 
outra pergunta, que encerra o texto de modo inquietante: "Soit! Mais un vide qui dispense la plénitude ne contient-il pas plus de réalité que n'en possède l'histoive dans son ensemble?" (ibidem, p.142). ${ }^{14}$

Em La chute dans le temps [A queda no tempo] (1964), obra publicada quatro anos depois de Histoire et utopie, há outras significativas reflexões cioranianas acerca do tempo. Dessa forma, para examinar essa "queda no tempo", o autor realça que, quando se contempla a passagem dos instantes, não se distingue nada além de uma sucessão sem conteúdo, tempo abstrato que perdeu sua substância, "variedade do nosso vazio". Mas o tempo não é feito para ser conhecido, e sim vivido. Pelo conhecimento de si mesmo, paga-se sempre muito caro: num universo explicado, nada teria sentido, porque a consciência significa distância. Ademais, "après avoir gâché l'éternité vraie, l'homme est tombé dans le temps, où il a réussi, sinon à prospérer, $d u$ moins à vivre: ce qui est certain, c'est qu'il s'en est accommodé. Le processus de cette chute et de cet accommodement a nom: Histoire" (Cioran, 1981, p.191). ${ }^{15}$ Ou seja, para o filósofo romeno, a história é o processo da queda do ser humano (que caiu da verdadeira eternidade), bem como de sua acomodação no tempo. Com a queda, o homem perdeu sua inocência original e adquiriu a consciência; e, almejando superar-se incessantemente, ele confunde devir e progresso. Tudo muda, mas raramente - talvez nunca - para melhor: o progresso é apenas a versão profana da queda.

No entanto, há ainda outra queda possível: cair não da eternidade, e sim do próprio tempo, e cair dele é cair da história. O tempo, porém, constitui o elemento vital do ser humano; então, restaria - como ruminação dessa perda dupla - apenas o tédio, que é o estado normal, o modo de sentir oficial de uma humanidade ejetada, finalmente, da história: “Avoir perdu et l'éternité et le temps! L'ennui est la rumination de cette double perte. Autant dive l'état normal, le mode de sentir officiel d'une humanité éjectée enfin de l'histoire" (ibidem, p.193). ${ }^{16}$ Chegando a esse extremo, o homem terá somente uma saída: conquistar uma segunda inocência e, recomeçando o conhecimento, edificar outra história, desagravada da antiga maldição.

Na História do cerco de Lisboa, aquele "não" que o revisor Raimundo Silva adiciona ao livro do historiador seria uma tentativa de edificar outra história? Como pondera Cioran, "il n'est nullement improbable qu'une crise individuelle devienne un jour le fait de tous et qu'elle acquière ainsi, non plus une signification psychologique, mais historique. Il ne s'agit pas là d'une simple bypothése; il est des signes qu'il faut s'habituer à live" (ibidem, p.191). ${ }^{17}$ A crise individual de Raimundo Silva, ao tornar-se um fato comum a todos os portugueses com o referido "não", adquire, portanto, uma significação histórica.

Além do "não" do revisor, outro tema central do romance é o cão rafeiro com o qual Raimundo Silva depara nas Escadinhas de S. Crispim, durante suas andanças por Lisboa, que, guiadas pelas informações contidas no texto do historiador, procuram refazer os caminhos do cerco: 
Senta-se num degrau para recobrar-se do susto, enxota um cão que se aproximara de focinho estendido, a beber-lhe os ares, e tira do bolso os papéis que separara do maço das provas, desdobra-os, alisa-os sobre os joelhos.

[...] O cão aproximou-se outra vez, agora Raimundo Silva olha-o apreensivo, sabe-se lá se não estará raivoso, uma ocasião, não se lembra onde, leu que um dos sinais do terrível mal é a cauda caída, e este rabo não demonstra grande vigor, mas será por causa do mau passadio, que bem se lhe veem as costelas ao bicho, e é sinal também, mas esse decisivo, a sinistra baba escorrendo das fauces e colmilhos, ora o rafeiro em presença, se saliva, será por estímulo de um cheiro de comida em preparação aqui nas Escadinhas de S. Crispim. O cão, tranquilizemo-nos, não está raivoso, se fosse no tempo dos mouros, talvez, mas agora, numa cidade como esta moderna, higiénica, organizada, até mesmo esta amostra de cão vadio é de estranhar, provavelmente tem-no salvado da rede frequentar de preferência este caminho desviado e íngreme, que requer perna ágil e fôlego de rapaz, bondades que não confluem inevitavelmente nos apanhadores de cães. (Saramago, 2019, p.75-6)

Marcos Aparecido Lopes (2005, p.322) sintetiza a importância de tal episódio nos seguintes termos: "Ao continuar sua redescoberta da cidade, mais precisamente ao descer as Escadinhas de S. Crispim, Raimundo Silva encontrará um cão rafeiro que lhe chamará a atenção. Motivo recorrente na narrativa, o cão rafeiro e faminto será associado à situação dos sitiados do cerco de Lisboa. Pode-se dizer que sua figura também constitui uma metáfora cuidadosamente elaborada ao longo do relato". E é essa metáfora da figura do cão que reaparece para encerrar a narrativa:

Na minha ideia, Ouroana vai voltar para a Galiza, e Mogueime irá com ela, e antes de partirem acharão em Lisboa um cão escondido, que os acompanhará na viagem, Por que pensas que eles se devem ir embora, Não sei, pela lógica deveriam ficar, Deixa lá, ficamos nós. A cabeça de Maria Sara descansa no ombro de Raimundo, com a mão esquerda ele acaricia-lhe o cabelo e a face. Não adormeceram logo. Sob o alpendre da varanda respirava uma sombra (Saramago, 2019, p. 386).

Nesse trecho final do romance, aqueles três estratos do tempo se confundem no presente da leitura: as histórias de Raimundo-Mogueime e Maria Sara-Ouroana apresentam-se, enfim, temporalmente indistintas. Quanto ao narrador, ele oscila, perdido no tempo, entre o presente e o passado: “descansa”, "acaricia-lhe”, “adormeceram”, “respirava”. E o futuro é uma sombra que respira sob o alpendre da varanda, ou seja, o futuro é utopia, um vazio que dispensa a plenitude religiosa, moral ou histórica. O cão utópico, sombra do tempo da ficção, é dúvida eterna que ressurge em eterno retorno. 


\section{Notas}

l “A ironia significará, então, coisas diferentes para os diferentes atores. Do ponto de vista do interpretador, a ironia é um movimento interpretativo e intencional: é criar ou inferir significado além e diferente do que é afirmado, juntamente com uma atitude em relação tanto ao dito quanto ao não dito. O movimento é usualmente desencadeado (e depois dirigido) por evidências textuais ou contextuais conflitantes ou por marcadores socialmente acordados. No entanto, do ponto de vista do que eu também (com reservas) chamarei o ironista, a ironia é a transmissão intencional tanto de informações quanto de atitudes avaliativas, para além daquilo que é explicitamente apresentado" (tradução minha).

2 "Hegel usou o termo dialética para designar um processo que dá origem a uma oposição, entre uma tese e uma antítese, que tem em si um impulso para ser resolvida por uma síntese, uma combinação em que os elementos conflitantes são preservados e de algum modo conciliados. Um exemplo é a oposição entre o ser e o não ser, superada na sua síntese, o devir. Toda a síntese dará por sua vez origem a um novo oposto, e assim por diante" (Mautner, 2011, p.212).

3 "A partir de Auguste Comte, a filosofia positiva e o positivismo são usados para designar uma mundividência que se considera estar em sintonia com a ciência moderna, rejeitando assim a superstição, a religião e a metafísica como formas pré-científicas de pensamento que irão dar lugar à ciência positiva no progresso contínuo da humanidade" (ibidem, p.590).

4 “Com este nome [materialismo histórico] Engels designou o cânon de interpretação histórica proposta por Marx, mais precisamente o que consiste em atribuir aos fatores econômicos (técnicas de trabalho e de produção, relações de trabalho e de produção) peso preponderante na determinação dos acontecimentos históricos. O pressuposto desse cânon é o ponto de vista antropológico defendido por Marx, segundo o qual a personalidade humana é constituída intrinsecamente (em sua própria natureza) por relações de trabalho e de produção de que o homem participa para prover às suas necessidades. A “consciência” do homem (suas crenças religiosas, morais, políticas, etc.) é resultado dessas relações, e não seu pressuposto. Esse ponto de vista foi defendido por Marx, sobretudo na obra Ideologia alemã (Deutsche Ideologie, 1845-46). Em vista disso, a tese do M. histórico é de que as formas assumidas pela sociedade ao longo de sua história dependem das relações econômicas predominantes em certas fases dela" (Abbagnano, 2007, p.652).

5 "Todas as sociedades são más" (tradução minha).

6 "Tendo abandonado a realidade pela ideia, e a ideia pela ideologia, o homem deslizou em direção a um universo derivado, em direção a um mundo de subprodutos, no qual a ficção adquire as virtudes de um dado primordial" (tradução minha).

7 "Uma feeria monstruosa" (tradução minha).

8 "Quadro no qual realizamos o contrário de nossas aspirações, no qual as desfiguramos sem cessar, a História não é, seguramente, de essência angélica. Ao considerá-la, não concebemos mais do que um desejo: promover a amargura na dignidade de uma gnose" (tradução minha).

9 "De boa vontade ou à força, apostamos no futuro, fazemos dele uma panaceia e, assimilando-o ao surgimento de um absolutamente outro tempo no interior do próprio 
tempo, consideramos [o futuro] uma duração inesgotável e, no entanto, acabada, como uma história intemporal. Contradição nos termos, inerente à esperança de um novo reino, de uma vitória do insolúvel no seio do devir. Nossos sonhos de um mundo melhor se fundam numa impossibilidade teórica” (tradução minha).

10 “Que orgulho descobrir que nada lhe pertence, que revelação!” (tradução minha).

11 "Caídos irremediavelmente na eternidade negativa, neste tempo disperso que somente se afirma se anulando, essência reduzida a uma série de destruições, soma de ambiguidades, plenitude cujo princípio reside no nada, vivemos e morremos em cada um de seus momentos, sem saber quando é, pois na verdade nunca é” (tradução minha).

12 “A utopia é um sonho cosmogônico ao nível da história” (tradução minha).

13 "Nada de paraíso, senão no mais profundo de nosso ser, e como no eu do eu" (tradução minha).

14 "Que seja! Mas um vazio que dispensa a plenitude não contém mais realidade do que possui a história como um todo?” (tradução minha).

15 "Depois de desperdiçar a eternidade verdadeira, o homem caiu no tempo, em que ele conseguiu, se não prosperar, ao menos viver: o que é certo é que ele aí se acomodou. O processo dessa queda e dessa acomodação tem nome: História”.

16 "Ter perdido a eternidade e o tempo! O tédio é a ruminação dessa dupla perda. Em outras palavras, o estado normal, o modo de sentir oficial de uma humanidade ejetada, enfim, da história" (tradução minha).

17 “Não é, de forma alguma, improvável que uma crise individual se torne um dia fato comum e que assim adquira, não mais um significado psicológico, mas histórico. Não se trata de uma simples hipótese; há sinais que é preciso se habituar a ler" (tradução minha).

\section{Referências}

ABBAGNANO, N. Dicionário de filosofia. Tradução da $1^{\text {a }}$ edição brasileira coordenada e revista por Alfredo Bosi; revisão da tradução e tradução dos novos textos por Ivone Castilho Benedetti. 5 ed. revista e ampliada. São Paulo: Martins Fontes, 2007.

AGOSTINHO. Confissões. Tradução do latim e prefácio de Lorenzo Mammì. 1 ed. São Paulo: Penguin Classics; Companhia das Letras, 2017.

ARNAUT, A. P. Memorial do Convento: história, ficção e ideologia. Coimbra: Fora do Texto, 1996.

Post-modernismo no romance português contemporâneo: fios de Ariadne, máscaras de Proteu. Coimbra: Almedina, 2002.

BERGSON, H. Duração e simultaneidade: a propósito da teoria de Einstein. Trad. Claudia Berliner; revisão técnica Bento Prado Neto. São Paulo: Martins Fontes, 2006.

BUENO, A. F. Três momentos do romance histórico de José Saramago. Boletim do CESP, Belo Horizonte, v.19, n.24, p.61-82, jan./jun. 1999.

CIORAN, E. M. La chute dans le temps. Paris: Gallimard, 1981.

Histoire et utopie. Paris: Gallimard, 2014. 
DELEUZE, G. Bergsonismo. Trad. Luiz B. L. Orlandi; tradução dos textos em apêndice de Lia de Oliveira Guarino e Fernando Fagundes Ribeiro. 2 ed. São Paulo: Editora 34, 2012 .

GOBBI, M. V. Z. A ficcionalização da história: mito e paródia na narrativa portuguesa contemporânea. São Paulo: Editora Unesp, 2011.

HUTCHEON, L. Irony's edge: the theory and politics of irony. London; New York: Routledge, 1995.

. Poética do pós-modernismo: história, teoria, ficção. Trad. Ricardo Cruz. Rio de Janeiro: Imago, 1991.

KANT, I. Ideia de uma história universal de um ponto de vista cosmopolita. Org. Ricardo R. Terra; trad. Rodrigo Naves e Ricardo R. Terra. São Paulo: Brasiliense, 1986.

KOSELLECK, R. Estratos do tempo: estudos sobre história. Trad. Markus Hediger. Rio de Janeiro: Contraponto; PUC-Rio, 2014.

Futuro passado: contribuição à semântica dos tempos históricos. Trad. Wilma

Patrícia Maas e Carlos Almeida Pereira; rev. César Benjamin. Rio de Janeiro: Contraponto; Ed. Puc-Rio, 2006.

LOPES, M. A. Rosário Profano: hermenêutica e dialética em José Saramago. Campinas, 2005. Tese (Doutorado em Teoria e História Literária) - Instituto de Estudos da Linguagem, Universidade Estadual de Campinas. Campinas, 2005.

MAUTNER, T. (Dir.) Dicionário de filosofia. Direção da edição portuguesa de Desidério Murcho; trad. Victor Guerreiro, Sérgio Miranda e Desidério Murcho. Lisboa: Edições 70, 2011.

NIETZSCHE, F. Sobre a utilidade e a desvantagem da história para a vida. Org. e trad. André Itaparica. São Paulo: Hedra, 2014.

Assim falou Zaratustra: um livro para todos e para ninguém. Trad., notas e posfácio de Paulo César de Souza. São Paulo: Companhia de Bolso, 2018.

SARAMAGO, J. História do Cerco de Lisboa. São Paulo: Companhia das Letras, 2019.

SILVA, T. C. C. José Saramago: entre a história e a ficção, uma saga de portugueses. Lisboa: Dom Quixote, 1989.

RESUMO - O propósito deste artigo é discutir a concepção de tempo na História do cerco de Lisboa (1989), de José Saramago. Para tanto, a partir da leitura do romance, recorre-se a considerações filosóficas - de Agostinho, Kant, Nietzsche, Bergson, Cioran e Koselleck - sobre tempo e história. Pretende-se, assim, evidenciar e analisar os estratos temporais dessa História saramaguiana com base nas relações entre ficção e filosofia.

PALAVRAS-CHAVE: Literatura portuguesa, José Saramago, História do Cerco de Lisboa, Tempo, Filosofia.

ABSTRACT - The purpose of this paper is to discuss the concept of time in the History of the Siege of Lisbon (1989), by José Saramago. To this end, based a reading of the novel, we turn to philosophical considerations - by Augustine, Kant, Nietzsche, Bergson, Ci- 
oran and Koselleck - about time and history. Thus, we intend to highlight and analyze the temporal strata of Saramago's History based on the relationships between fiction and philosophy.

KEYWORDS: Portuguese literature, José Saramago, History of the Siege of Lisbon, Time, Philosophy.

Marcelo Lachat é professor adjunto do Departamento de Letras da Universidade Federal de São Paulo (Unifesp). Doutor em Literatura Portuguesa pela Universidade de São Paulo (USP). @ - marlachat@hotmail.com /

https://orcid.org/0000-0003-0353-8618

Recebido em 19.12.2019 e aceito em 12.2.2020.

${ }^{\text {I }}$ Departamento de Letras, Universidade Federal de São Paulo, Guarulhos, São Paulo, Brasil. 